\title{
Quality of Life, Physical Activity and Risk Behaviors: A Case Study in Mechanical Engineering Students
}

\author{
Gustavo Levandoski ${ }^{1}$, Luiz Alberto Pilatti², Paulo Henrique Trombetta Zannin ${ }^{3}$ \\ ${ }^{1}$ Federal University of Grande Dourados, Dourados, Brazil \\ ${ }^{2}$ Federal Technological University of Paraná, Curitiba, Brazil \\ ${ }^{3}$ Laboratory of Environmental and Industrial Acoustics and Acoustic Comfort, Federal University of Paraná, Curitiba, Brazil \\ Email: glevandoski@gmail.com,paulo.zannin@pesquisador.cnpq.br, paulo.zannin@gmail.com
}

How to cite this paper: Levandoski, G., Pilatti, L.A. and Zannin, P.H.T. (2016) Quality of Life, Physical Activity and Risk Behaviors: A Case Study in Mechanical Engineering Students. Open Journal of Social Sciences, 4, 19-27.

http://dx.doi.org/10.4236/jss.2016.410002

Received: August 23, 2016

Accepted: September 27, 2016

Published: September 30, 2016

Copyright $\odot 2016$ by authors and Scientific Research Publishing Inc. This work is licensed under the Creative Commons Attribution International License (CC BY 4.0).

http://creativecommons.org/licenses/by/4.0/ (c) (i) Open Access

\begin{abstract}
This paper describes a transversal study involving 296 undergraduate mechanical engineering students, using a descriptive probabilistic approach. The purpose of this study was to evaluate the level of life quality and physical activity of the participants, comparing them to variables indicative of health risk factors. It was found that $70.6 \%$ of the study population evaluated their life quality standard as good or very good. With respect to their level of physical activity, 38.8\% of the participants are physically inactive in their leisure time. As for the prevalence of risk factors, 3.7\% of them belong to high risk groups: sedentary, overweight, and/or smokers. In addition, the hypothesis of a direct correlation between the level of physical fitness and life quality is confirmed.
\end{abstract}

\section{Keywords}

Quality of Life, Physical Activity, Exercises, Risk Factors, Sedentary Lifestyle, Overweight

\section{Introduction}

Studies of the prevalence of risk behaviors in different population sat the beginning of the last decade were common only in countries of the northern hemisphere, because epidemiological surveillance do not focus solely on the aspects of mortality and morbidity [1]. Currently, the centralization of studies on risk behavior of populations focuses primarily on chronic on-communicable diseases, with the premise warning about epidemics resulting from risk factors caused by negative lifestyle of populations, asso- 
ciated with the leading causes of death [2] [3].

Several studies have demonstrated the correlation between a sedentary lifestyle [3], smoking and overweight affects people's health negatively, leading to lower levels of quality of life and increasing the incidence of diseases [4] [5]. Data published by Brazil's Ministry of Health at the beginning of the last decade indicated that a sedentary lifestyle, smoking, and poor nutrition were responsible for over $50 \%$ of the total risk of developing any type of chronic disease [6].

Engaging in regular physical activity is recognized as one of the main elements that contribute toward the prevention of risk factors for health [7]. A study conducted in Northeast and Southeast Brazilin the 1990s found that the percentage of physical inactivity (defined as less than 150 minutes per week of moderate physical activity or 60 minutes a week of vigorous physical activity during leisure time) had already reached 96.7\% [8]. Currently, the percentage of physical inactivity during leisure time in Brazil's adult population differs according to the region, 52\% [9] in southern cities, $65.4 \%$ [10] in the Southeast, $47.5 \%$ [11] in the Midwest region, and 57.6\% [12] in the Northeast. This analysis indicates that society does not engage in the minimum recommended levels of physical activity recommended by the American University of Sports Medicine, which would enable individuals to improve their fitness levels and thus contribute to a better quality of life.

The term quality of life is associated with abstract and everyday perceptions about the life style of each individual [13] [14]. However, its interrelationship with the area of health sciences emphasizes that the daily practice of physical exercise is essential to the creation of positive habits that provide a change of lifestyle, thus acting as one of the main factors that contribute toward improved health [15]-[17]. Among young Brazilian university students, the literature describe students of physical education [17], psychology [18], law [19], nursing [12] [16] [20], and medicine [19] [21]. These studies have shown that regular physical activity helps reduce risk factors and increases the level of quality of life, especially among engineering students, where we can see a shortage of studies.

The correlations between the quality of life domains and physical activity levels are strong and positive for both genders, concluding that the domains of quality of life and physical activity level differ between the genders and show positive strong relationships in undergraduate students [17]. Thus, this work involved an investigation of the level of quality of life and physical activity, and their correlation with the behavioral risk factors of young mechanical engineering students.

\section{Materials and Methods}

This is a cross-sectional study with a descriptive probabilistic sign conducted with mechanical engineering students enrolled at the Federal University of Paraná-UFPR. The study population consisted of 536 students of both sexes, arranged in ten periods. To calculate the sample, a sampling error of $4 \%$ and a confidence level of $95 \%$ were adopted, making a total of 296 participants in the study.

Intervening variables (sex, daily use of tobacco) were used as control, as well as the 
level of physical activity (International Physical Activity Questionnaire-IPAQ, short version) [22], the level of quality of life (Quality of Life Questionnaire of the World Health-WHOQOL-bref) [14], and nutritional status, also adopting the criteria of the World Health Organization (WHO) [13], which verifies the overall level of quality of life, plus four domains: physical, psychological, social and environmental. Considering a BMI of $<24.9 \mathrm{~kg} / \mathrm{m}^{2}$ as the limit between normal weight and overweight. Height and total body mass measurements were obtained from self-reported information, whose validity is described in several studies [23].

All the individuals of the sample were informed about the procedures through a Free Prior and Informed Consent Form, describing the procedures and purpose of the research, according to the "Guidelines and Standards Regulating Research Involving Human Beings" (196/96), published by the National Health Commission and approved by the Research Ethics Committee of Ponta Grossa State University-UEPG.

The statistical analysis was performed using the Statistical Package for the Social Sciences (SPSS, version 14.0) for Windows. The Kolmogorov-Smirnov test was used to check data normality. Due to this test, nonparametric inferences were used for some variables (Mann-Whitney, Kruskal-Wallis tests), and central tendency measures were used in the descriptive analysis of the data, adopting a value of $\mathrm{p}<0.05$.

\section{Results}

With regard to the total number of participants, it was found that the average age of the population was 20.6 years, with ages ranging from 17 to 30 years, most of them, $77.7 \%$, males, $98.6 \%$ single, $14.1 \%$ smokers and $26.3 \%$ classified as overweight.

When asked "How would you rate your quality of life?" $45.9 \%$ answered "good" (fourth point on a five-point Likert scale). The average level of quality of life "general" is analyzed based on the WHOQOL-bref syntax, which results in a scale of $(0-100$ points) and on which a good quality of life should be indicated by a result of close to 100. Based on this syntax, this study found a general health value of 71.4 points.

Table 1 lists the mean values and standard deviations of the overall level of quality of life of the participants, subdivided into its respective domains (Physical Domain- $\mathrm{PhD}$, Psychological Domain-PsD, Social Relationships Domain-SRD and Environment Domain-ED), resulting from the evaluation using the WHOQOL-bref syntax, as well as the frequency of the level of physical activity based on the IPAQ classification.

The level of physical activity obtained with the IPAQ indicates that the highest

Table 1. Analysis of the domains of Quality of Life Level (WHOQOL-bref) and Physical Activity (IPAQ) of the participants of this study $(n=296)$.

\begin{tabular}{|c|c|c|c|c|c|}
\hline WHOQOL & GERAL & $\mathrm{PhD}$ & PsD & SRD & ED \\
\hline$($ Mean $\pm \mathrm{PhD})$ & $71.4 \pm 18.7$ & $67.3 \pm 15.2$ & $67.8 \pm 15.5$ & $69.2 \pm 18.9$ & $64.0 \pm 12.9$ \\
\hline IPAQ & Sedentary & $\begin{array}{c}\text { Irregularly } \\
\text { active-B }\end{array}$ & $\begin{array}{c}\text { Irregularly } \\
\text { active-A }\end{array}$ & Active & Very active \\
\hline (Frequency) & $59(19.9 \%)$ & $56(18.9 \%)$ & 77 (26.0\%) & $56(18.9 \%)$ & 48 (16.2\%) \\
\hline
\end{tabular}


percentage (26\%) of participants is on the third sublevel described as "irregularly active-A." Individuals who engage in $150 \mathrm{~min} /$ week of moderate or intense physical activity are classified in this sublevel. However, when the participants classified in the groups (A-irregularly active, active and very active) were added up, the moderately and intensely active participants represented $61.2 \%$.

Table 2 compares the domains of quality of life obtained with the WHOQOL-bref in terms of sex, age and major risk factors (overweight, smoking and physical inactivity).

As can be seen, male participants showed statistically higher average scores for quality of life than women, except for the physical domain. With regard to risk factors, the participants classified in the risk group obtained significantly lower averages in all the domains of quality of life than the group classified as normal.

\section{Discussion}

In response to the question "How would you rate your quality of life?" $70.6 \%$ of the

Table 2. Comparison of Level of Quality of Life with respect to risk factors.

\begin{tabular}{|c|c|c|c|c|c|c|}
\hline & $\mathrm{n}$ & OVERALL & $\mathrm{PhD}$ & PsD & SRD & ED \\
\hline $\operatorname{SEX}(p)$ & & $0.009^{*}$ & 0.254 & $0.012^{*}$ & $0.003^{*}$ & $0.042^{*}$ \\
\hline Men & 230 & $72.9 \pm 18.0$ & $67.8 \pm 15.3$ & $69.0 \pm 15.4$ & $71.0 \pm 18.8$ & $64.9 \pm 13.1$ \\
\hline Women & 66 & $66.0 \pm 20.3$ & $65.4 \pm 15.1$ & $63.6 \pm 15.2$ & $63.1 \pm 18.1$ & $61.2 \pm 12.0$ \\
\hline AGE (p) & & $0.013^{*}$ & 0.100 & 0.482 & 0.156 & 0.116 \\
\hline$<=20$ years & 160 & $73.9 \pm 18.0$ & $68.6 \pm 14.7$ & $68.4 \pm 15.3$ & $70.7 \pm 19.2$ & $65.1 \pm 13.0$ \\
\hline$>=21$ years & 136 & $68.4 \pm 19.1$ & $65.7 \pm 15.7$ & $67.1 \pm 15.7$ & $67.5 \pm 18.5$ & $62.8 \pm 12.8$ \\
\hline BMI (p) & & $0.001^{*}$ & $0.006^{*}$ & $0.001^{*}$ & $0.001^{*}$ & $0.021^{*}$ \\
\hline Normal & 209 & $73.8 \pm 18.0$ & $68.9 \pm 15.0$ & $69.6 \pm 15.0$ & $71.8 \pm 18.6$ & $65.2 \pm 12.6$ \\
\hline Overweight & 78 & $65.5 \pm 19.1$ & $63.2 \pm 15.7$ & $62.8 \pm 16.0$ & $63.1 \pm 18.6$ & $61.3 \pm 13.6$ \\
\hline SMOKER (p) & & $<0.001^{*}$ & $<0.001^{\star}$ & $<0.001^{\star}$ & $<0.001^{\star}$ & $<0.001^{\star}$ \\
\hline No & 252 & $73.4 \pm 17.8$ & $69.2 \pm 14.5$ & $69.4 \pm 14.7$ & $71.3 \pm 17.9$ & $65.1 \pm 12.8$ \\
\hline Yes & 44 & $59.9 \pm 19.9$ & $56.4 \pm 14.9$ & $58.7 \pm 17.1$ & $57.1 \pm 20.1$ & $57.8 \pm 11.8$ \\
\hline IPAQ (p) & & $<0.001^{\star}$ & $<0.001^{\star}$ & $<0.001^{*}$ & $0.002^{*}$ & $<0.001^{\star}$ \\
\hline Sedentary & 59 & $66.6 \pm 18.0 \mathrm{xy}$ & $61.5 \pm 13.8 x y$ & $61.4 \pm 16.6 x y$ & $65.5 \pm 18.6$ & $59.5 \pm 11.9 x$ \\
\hline Irreg. Active B & 56 & $65.8 \pm 17.1 \mathrm{xy}$ & $63.9 \pm 15.0 x y$ & $64.3 \pm 14.4 \mathrm{x}$ & $62.3 \pm 18.1 \mathrm{xy}$ & $60.3 \pm 11.1 x$ \\
\hline Irreg. Active A & 77 & $68.9 \pm 18.6 x$ & $66.6 \pm 13.1$ & $67.3 \pm 14.5$ & $71.1 \pm 18.8$ & $63.1 \pm 12.0 \mathrm{x}$ \\
\hline Active & 56 & $77.4 \pm 16.2$ & $71.2 \pm 13.6$ & $72.0 \pm 13.5$ & $73.5 \pm 15.2$ & $66.4 \pm 12.7$ \\
\hline Very active & 48 & $80.9 \pm 19.2$ & $75.0 \pm 18.0$ & $75.7 \pm 15.0$ & $74.1 \pm 21.7$ & $72.6 \pm 13.6$ \\
\hline
\end{tabular}

${ }^{*} \mathrm{p}<0.05(\mathrm{x}=$ other than "very active"; $\mathrm{y}=$ other than "active"). 
participants rated their quality of life as "good" and "very good" (on a 5-point Likert scale, representing the highest scores). In a study by Chehuen Neto [19], 90.1\% of law students and $86.75 \%$ of medical students rated their quality of life as "good" and "very good." In Arronqui's study [15], 60.1\% of nursing students considered their quality of life "good."

In response to the question: "How would you rate your quality of life?" $70.6 \%$ of the participants rated their quality of life as "good" and "very good" (on a 5-point Likert scale, representing the highest scores). In a study by Chehuen Neto [19], 90.1\% of law students and $86.75 \%$ of medical students rated their quality of life as "good" and "very good." In Arronqui's study [15], 60.1\% of nursing students considered their quality of life "good".

Among university students, this score was higher in studies involving psychology students in Rio Grandedo Sul 71.3\% [18]; Physical Education students in Paraná 70.9\% [24]; and nursing students in Santa Catarina 64\% [20], and lower than the study involving young athletes in Paraná 73\% [25].

Students' perception of quality of life maybe closely associated with their desire to work in their future profession. This perception may cause these levels to increase or decrease due to difficulties encountered in their professional activity. In a studyof46students concluding their medical studies, Ramos Dias [21] found that in their daily lives, long work shifts, medical residency examinations, and frustrations due to the inability to save a life can lead to higher levels of stress.

As for the domains of quality of life, the highest and lowest scores were found, respectively, in the domains of "social relations" and "environment". The same result was found in studies involving young athletes in State of Paraná [25]; medical and law students in State of Minas Gerais [19] and nursing students in State of Santa Catarina [20]. In contrast, in studies involving students of Psychology [18], Physical Education [24], Nursing [16] and Medicine [21], the highest scores were in the "physical" domain and the lowest in the "environment" domain.

One factor that corroborates the above cited studies is that the environment domain scored the lowest values among university students. According to Saupe [20], the evaluation of the environmental domain may be related to the climate of insecurity and uncertainty of Brazilian society, especially students, face regarding a prosperous life as a citizen.

The study by Silva [26] found that the sum of the "active" and "very active" sublevels generated highly varying values among students from several areas such as Biology 86.9\%, Physical Education 90\%, Pharmacy 56\% and Dentistry 61.1\%. Rodrigues [27], who assessed the level of physical activity of university students from several areas (biomedical, human and exact sciences) in the state of Tocantins, found that the highest proportion $51.1 \%$ was, represented by "active" individuals. Mc Guirre [28] reported that individuals residing in regions with warmer climates may practice more physical activity.

Rech [23] reported that $2.7 \%$ of physical education students presented a low level of physical activity. However, when comparing medical and physical education students, 
it should be noted that the latter must perforce have physical activity included as a component of their curriculum [29].

A sedentary lifestyle is a major risk factor for the development of chronic egenerativen on-communicable diseases which can be modified by a simple change in lifestyle habits in Western societies [4]. However, a large part of the population does not present the minimum patterns of physical activity recommended for maintaining the health status [30]. In the present study, among the participants classified as "sedentary" and those with a tendency to be "irregularly active- $\mathrm{B}$ ", $38.8 \%$ showed poor physical exercise habits. This tendency for a sedentary lifestyle is confirmed particularly after the individual enters the work market. A study by Elsangedy [31], based on the IPAQ, found that $48.2 \%$ of the university professors at a private university in State of Paraná were sedentary.

From the standpoint of the participants' sex, men reported higher levels of quality of life in all the domains than women. In a study involving physical education students, Cieslak [24] found a statistical difference only in the domain of "social relations," in which women presented the higher average. Male nursing students showed statistically higher averages in the "physical" and "psychological" domains [16]. In contrast, university professors in São Paulo showed no gender-related differences in the domains of quality of life [32].

A comparison of the participants' age in the item "overall quality of life" indicated that younger students reported a higher level than older ones in this study. This can be attributed to the fact that older students exhibit higher risk behavior. In a similar comparison, Eurich [16] did not find age-related differences among nursing students. In a study involving medical students in São Paulo, the difference found among the participants was in the domain of social relationships, in which older students scored the higher rate; however, the relationship of this variable was evaluated among beginning and final year students [21]. Many of the risk behaviors are found among students who are close to graduation, precisely because of their greater social contribution due to their longer time in this social network [5] [27].

In this study, a prevalence of $14.8 \%$ of frequent smoking was found, with $11.4 \%$ men and 3.3 women. Rodrigues [27] reported that this prevalence was $19.5 \%, 10.8 \%$ men and $5.5 \%$ women. In a probabilistic study involving students from the University of Brasilia, smoking showed a prevalence of $14.7 \%$, with $9 \%$ representing regular smokers and $5.7 \%$ occasional smokers [33].

In view of this prevalence of smoking and overweight, Table 2 indicates that in all the domains indicated by the quality of life index, non-smoking students with a normal body mass index showed the highest levels of quality of life $(p<0.001)$.

In the quest to achieve a change of lifestyle, there is evidence that just one day of abstinence suffices to improve the body's physiological response. A study to determine the effect of smoking abstinence on the cardiovascular responses of sedentary female smokers reported that just one day of abstinence already improved their hemodynamic parameter sat rest in response to sub maximal graded exercise [34].

An analysis of the prevalence of risk behaviors indicated that 11 students $3.7 \%$ pre- 
sented the main characteristics of chronic on-communicable diseases (physical inactivity, overweight and smoking), which are associated with the leading causes of death. It is known that individuals older than 25 years of age present a higher prevalence of physical inactivity and smoking, although this was not confirmed in our study [27]. A comparison of the variables "level of quality of life" and "physical activity" confirmed the hypothesis that the higher the fitness level the better the quality of life [35]. Some limitations can be identified in this study as the increase of the sample allowing greater support to statistics.

\section{Conclusions}

The present study found a low prevalence (3.7\%) of participants with behavioral risk factors (physical inactivity, overweight and smoking). However, participants presenting at least one of these behaviors showed a tendency for a significantly lower level of quality of life than the others.

Underage students showed slightly more positive risk behaviors than the other participants, and it was found that nonsmokers with normal body mass index presented significantly better levels of quality of life.

With regard to the level of physical activity, $38.8 \%$ of the participants reported that they were physically inactive in their leisure time. The overall level of quality of life of this group was statistically significantly lower than that of the physically "active" and "very active" participants, except in the domain of social relations.

\section{References}

[1] Barros, M.V.G. and Nahas, M.V. (2001) Risk Behaviors, Health Self-Assessment and Perception of Stress among Industrial Workers. Revista de Saúde Pública, 35, 554-563. http://dx.doi.org/10.1590/S0034-89102001000600009

[2] Blay, S.L. and Marchesoni, M.S.M. (2011) Association among Physical, Psychiatric and Socioeconomic Conditions and WHOQOL-Bref Scores. Reports in Public Health, 27, 677686. http://dx.doi.org/10.1590/s0102-311x2011000400007

[3] Silva, D.A.S. and Petroski, E.L. (2011) Factors Associated with the Level of Participation in Physical Activity of Students at a Public University in Southern Brazil. Ciência \& Saúde Coletiva, 16, 4087-4094.

[4] Bauman, A. and Craig, C.L. (2005) The Place of Physical Activity in the WHO Global Strategy on Diet and Physical Activity. International Journal of Behavioral Nutrition and Physical Activity, 24, 2-10.

[5] Farias Jr., J.C. and Lopes, A.S. (2004) Health Risk Behaviors in Adolescents. Revista Brasileira de Ciência e Movimento, 12, 7-12.

[6] Ministry of Health (2002) National Program for the Promotion of Physical Activity "Shake It, Brazil": Physical Activity and Its Contribution to Quality of Life. Revista de Saúde Pública, 36, 254-256.

[7] Hallal, P.C., Matsudo, S.M., Matsudo, V.K.R., et al. (2005) Physical Activity in Adults from Two Brazilian Areas: Similarities and Differences. Reports in Public Health, 21, 573-580. http://dx.doi.org/10.1590/s0102-311x2005000200024

[8] Monteiro, C.A., Conde, W.L., Matsudo, S.M., Matsudo, V.R., Bonseñor, I.M. and Lotufo, 
P.A. (2003) The Descriptive Epidemiology of Leisure Physical Activity in Brazil, 1996-1997.

Revista Panamericana de Salud Pública, 14, 246-254.

http://dx.doi.org/10.1590/S1020-49892003000900005

[9] Knuth, A.G., Bacchieri, G., Victora, C.G. and Hallal, P.C. (2010) Changes in Physical Activity among Brazilian Adults over a 5-Year Period. Journal of Epidemiology \& Community Health, 64, 591-595. http://dx.doi.org/10.1136/jech.2009.088526

[10] Zanchetta, L.M., Barros, M.B.A., Galvão, C.C.L., Moisés, C.L.G. and Porto, A.M.C.G. (2010) Physical Inactivity and Associated Factors in Adults. Revista Brasileira de Epidemiologia, 13, 387-399. http://dx.doi.org/10.1590/S1415-790X2010000300003

[11] Thomaz, P.M.D., Costa, T.H.M., Silva, E.F. and Hallal, P.C. (2010) Factors Associated with Physical Activity in Adults, Brasília, DF. Revista de Saúde Pública, 44, 894-900. http://dx.doi.org/10.1590/S0034-89102010005000027

[12] Reis, H.F.C., Ladeia, A.M.T., Passos, E.C., Santos, F.G.O. and Wasconcellos, L.T. (2009) Prevalence and Variables Associated with Physical Inactivity in Individuals of High and Low Socioeconomic Status. Brazilian Archives of Cardiology, 92, 203-208.

[13] World Health Organization (1998) Obesity: Preventing and Managing the Global Epidemic. Geneva.

[14] Fleck, M.P.A., Louzada, S., Xavier, M., Chachamovich, E., Vieira, G. and Santos, L. (2000) Application of the Portuguese Version of the Abbreviated Instrument for Assessing Quality of Life, "WHOQOL-Bref”. Revista de Saúde Pública, 34, 178-183. http://dx.doi.org/10.1590/S0034-89102000000200012

[15] Arronqui, G.V., Lacava, R.M.V.B., Magalhães, S.M.F. and Goldman, R.E. (2011) Perceptions of Final Year Nursing Students on Their Quality of Life. Acta Paulista de Enfermagem, 24, 762-765. http://dx.doi.org/10.1590/S0103-21002011000600005

[16] Eurich, R.B. and Kluthcovsky, A.C.G.C. (2008) Assessment of the Quality of Life of First and Fourth Year Nursing Students: Influence of Sociodemographic Variables. Revista de Psiquiatria, 30, 211-220.

[17] Cieslak, F., Cavazza, J.F., Lazarotto, L., Titski, A.C.K., Stefanello, J.M.F. and Leite, N. (2012) Analysis of the Quality of Life and Physical Activity Level in Undergraduate Students. Revista da Educação Físical UEM, 23, 251-260.

[18] Costa, C.C.D., Bastiani, M.D., Geyer, J.G., Calvetti, P.Ü. and Muller, M.C. (2008) Quality of Life and Spiritual Well-Being in Psychology Students. Psicologia em Estudo, 13, 249-255. http://dx.doi.org/10.1590/S1413-73722008000200007

[19] Chehuen Neto, J.Á., Sirimarco, M.T., Baratti, A.B., Marques, F.S. and Pittondo, M.S. (2008) Quality of Life of Medical and Law Students. HU Revista, 34, 197-203.

[20] Saupe, R., Nietche, E.A., Cestari, M.E., Giorgi, M.D.M. and Krahl, M. (2004) Quality of Life of Nursing Students. Revista Latino-Americana de Enfermagem, 12, 636-642.

[21] Ramos-Dias, J.C., Libardi, M.C., Zillo, C.M., Igarashi, M.H. and Senger, M.H. (2010) Quality of Life among 100 Medical Students at the Catholic University in Sorocaba, São Paulo. Revista Brasileira de Educação Médica, 34, 116-123. http://dx.doi.org/10.1590/S0100-55022010000100014

[22] Matsudo, S., Araujo, T., Matsudo, V., Andrade, D. and Andrade, E. (2001) International Physical Activity Questionnaire (IPAQ): A Study of Its Validity and Reproducibility in Brazil. Revista Brasileira de Atividade Física e Saúde, 6.

[23] Rech, C.R., Araújo, E.D.S. and Vanat, J.R. (2010) Self-Perception of Body Image in the Physical Education Course Students. Revista Brasileira de Educação Física e Esporte, 24, 285-292. http://dx.doi.org/10.1590/S1807-55092010000200011 
[24] Cielask, F., Levandoski, G., Santos, T.K., Vilela Jr., G.B. and Leite, N. (2007) Relationship between the Level of Quality of Life and Physical Activity of Physical Education Students. Fitness \& Performance Journal, 6, 357-361. http://dx.doi.org/10.3900/fpj.6.6.357.e

[25] Cieslak, F., Levandoski, G., Quadros, M.T.B., Santos, T.K. and Vilela Jr., G.B. (2008) Relationship between Quality of Life and Anthropometric Parameters among Young Athletes Youth in the Municipality of Ponta Grossa-PR. Revista da Educação Físical UEM, 19, 225 232.

[26] Silva, G.S.F., Bergamaschine, R., Rosa, M., Melo, C. and Miranda, R. (2007) Assessment of the Level of Physical Activity among Final Year Students in the Areas of Health/Biology. Revista Brasileira de Medicina do Esporte, 13, 39-42.

[27] Rodrigues, E.S.R., Cheik, N.C. and Mayer, A.F. (2008) Level of Physical Activity and Smoking in Undergraduate Students. Revista de Saúde Pública, 42, 672-678. http://dx.doi.org/10.1590/S0034-89102008000400013

[28] Mcguire, M.T., Hannan, P.J., Neumark-Sztainer, D., Cossrow, N.H. and Story, M. (2002) Parental Correlates of Physical Activity in a Racially/Ethnically Diverse Adolescent Sample. Journal of Adolescent Health, 30, 253-256. http://dx.doi.org/10.1016/S1054-139X(01)00392-5

[29] Marcondelli, P., Costa, T.H.M. and Schmitz, B.A.S. (2008) Physical Activity Level and Food Intake Habits of University Students from 3 to 5 Semester in the Health Area. Revista de Nutrição, 21, 39-47. http://dx.doi.org/10.1590/S1415-52732008000100005

[30] Matsudo, V.K.R. and Matsudo, S.M.M. (2000) Evidence of the Importance of Physical Activity on Cardiovascular Diseases and Health. Diagnostics and Treatment, 5, 10-17.

[31] Elsangedy, H.M., Krinski, K., Buzzachera, C.F., Cieslak, F. and Silva, S.G. (2008) Level of Physical Activity and Its Possible Barriers among University Professors in Toledo-PR. Lecturas Educación Física y Deportes, 12.

[32] Martinez, K.A.S.C., Vitta, A. and Lopes, E.S. (2009) Assessment of the Quality of Life of University Professors in the City of Bauru-SP. Salusvita, 28, 217-224.

[33] Andrade, A.A.A., Bernardo, A.C.C., Viegas, A.C.C., Ferreira, D.B.L., Gomes, T.C. and Sales, M.R. (2006) Prevalence and Characteristics of Smoking among Young People at the University of Brasilia. Jornal Brasileiro de Pneumologia, 32, 23-28. http://dx.doi.org/10.1590/S1806-37132006000100007

[34] Pureza, D.Y., Sargentini, L., Laterza, R., Flores, L.J.F. and Irigoyen, M.C. (2007) Cardiovascular Effects of Smoking Abstinence at Rest and during Submaximal Exercise on Young Female Smokers. Revista Brasileira de Medicina do Esporte, 13, 292-296. http://dx.doi.org/10.1590/S1517-86922007000500003

[35] Haskell, W.L., Lee, I.M., Pate, R.R., Powell, K.E. and Blair, S.N. (2007) Physical Activity and Public Health: Updated Recommendation for Adults from the American College of Sports Medicine and the American Heart Association. Medicine \& Science in Sports \& Exercise, 39, 1423-1434. http://dx.doi.org/10.1249/mss.0b013e3180616b27 
Submit or recommend next manuscript to SCIRP and we will provide best service for you:

Accepting pre-submission inquiries through Email, Facebook, LinkedIn, Twitter, etc. A wide selection of journals (inclusive of 9 subjects, more than 200 journals)

Providing 24-hour high-quality service

User-friendly online submission system

Fair and swift peer-review system

Efficient typesetting and proofreading procedure

Display of the result of downloads and visits, as well as the number of cited articles

Maximum dissemination of your research work

Submit your manuscript at: http://papersubmission.scirp.org/

Or contact jss@scirp.org 